\title{
Improved Low Resistance Contacts of Ni/Au and Pd/Au to p-Type GaN Using a Cryogenic Treatment
}

\author{
Mi-Ran Park ${ }^{1}$, Wayne A. Anderson ${ }^{1}$ and Seong-Ju Park ${ }^{2}$ \\ ${ }^{1}$ State University of New York at Buffalo, Department of Electrical Engineering, \\ Amherst, NY, U.S.A. \\ ${ }^{2}$ Kwangju Institute of Science and Technology, Department of Materials Science and \\ Engineering, Kwangju, Korea
}

\begin{abstract}
A low resistance Ohmic contact to p-type $\mathrm{GaN}$ is essential for reliable operation of electronic and optoelectronic devices. Such contacts have been made using $\mathrm{Ni} / \mathrm{Au}$ and $\mathrm{Pd} / \mathrm{Au}$ contacts to p-type $\mathrm{Mg}$-doped $\mathrm{GaN}\left(1.41 \times 10^{17} \mathrm{~cm}^{-3}\right)$ grown by metalorganic chemical vapor deposition (MOCVD) on (0001) sapphire substrates. Thermal evaporation was used for the deposition of those metals followed by annealing at temperatures of $400 \sim 700{ }^{\circ} \mathrm{C}$ in an oxygen and nitrogen mixed gas ambient, then subsequently cooled in liquid nitrogen which reduced the specific contact resistance from the range of $9.46 \sim 2.80 \times 10^{-2} \Omega \mathrm{cm}^{2}$ to $9.84 \sim 2.65 \times 10^{-4} \Omega \mathrm{cm}^{2}$ for $\mathrm{Ni} / \mathrm{Au}$ and from the range of $8.35 \sim 5.01 \times 10^{-4} \Omega \mathrm{cm}^{2}$ to $3.34 \sim 1.80 \times 10^{-4} \Omega \mathrm{cm}^{2}$ for $\mathrm{Pd} / \mathrm{Au}$. The electrical characteristics for the contacts were examined by the current versus voltage curves and the specific contact resistance was determined by use of the circular transmission line method (cTLM). The effects of the cryogenic process on improving Ohmic behavior (I-V linearity) and reducing the specific contact resistance will be discussed from a microstructural analysis which reveals the metallurgy of Ohmic contact formation.
\end{abstract}

\section{INTRODUCTION}

Great interest exists in the III-nitride semiconductors since the successful development in growth of $\mathrm{GaN}$ based materials and operation of electronic and optoelectronic devices such as blue and green light emitting diodes (LEDs) and laser diodes (LDs) [1,2,3,4]. The formation of stable and reliable low resistance ohmic contacts to p-type GaN has been a problem in achieving good performance of those devices. For devices with large contact areas such as LEDs and LDs, the specific contact resistance $\left(\rho_{c}\right)$ between $10^{-4}$ to $10^{-6}$ $\Omega \mathrm{cm}^{2}$ is considered acceptable and for devices with smaller contact areas, values of $\rho_{\mathrm{c}}$ between $10^{-5}$ to $10^{-7} \Omega \mathrm{cm}^{2}$ are necessary [5]. Bilayer metal schemes such as $\mathrm{Ni} / \mathrm{Au}$ and $\mathrm{Pd} / \mathrm{Au}$ were studied by many groups $[6,7,8]$. These have been studied due to the stable electrical and thermal properties and the high work function which is one criteria to form low resistance Ohmic contacts to p-type materials.

The effects of cryogenic cooling after heat treatment on the formation of $\mathrm{Ni} / \mathrm{Au}$ and $\mathrm{Pd} / \mathrm{Au}$ contacts are presented in this paper. We also compare these effects on forming $\mathrm{Ni} / \mathrm{Au}$ and $\mathrm{Pd} / \mathrm{Au}$ contacts annealed in a combined $\mathrm{O}_{2} / \mathrm{N}_{2}$ gas ambient. High temperature annealing may degrade homogeneity possibly caused by spiking of metals between themselves or between metal and semiconductor due to the differences in thermodynamic properties of materials. Annealing was conducted in an oxygen and nitrogen mixed gas ambient as reported by Y. Koide et al. [6]. This is to remove hydrogen atoms contained in Mg-doped GaN epilayers. Removing hydrogen atoms results in the increase of the hole concentration and decrease of the contact resistance. Annealing in nitrogen gas ambient is 
believed to avoid nitrogen vacancies which act as doners. We expected that cryogenic treatment would reduce disadvantages from the discrepancy in thermodynamic properties of materials during cooling the heated samples to give improved Ohmic behavior. With cryogenic treatment, the changes of electrical and structural properties have been examined.

\section{EXPERIMENT}

The metal contacts were made on GaN films grown by metalorganic chemical vapor deposition (MOCVD) on (0001) sapphire substrates. The GaN films consisted of the $\mathrm{Mg}$ doped p-type $\mathrm{GaN}$ with a thickness of $2 \mu \mathrm{m}$ on a $30 \mathrm{~nm}$ thick $\mathrm{GaN}$ buffer layer. The hole concentration of the $\mathrm{p}-\mathrm{GaN}$ layer was $1.41 \times 10^{17} \mathrm{~cm}^{-3}$ and the resistivity was $3.5 \Omega \mathrm{cm}$. The samples were sequentially ultrasonically cleaned in trichloroethylene, acetone and methanol, then rinsed in $18 \mathrm{M} \Omega$ de-ionized (DI) water. The cleaned samples were chemically etched in boiling aqua regia of $\mathrm{HNO}_{3}: \mathrm{HCl}=1: 3$ for 10 minutes to remove the native oxide and the contamination of the GaN surface as suggested by J. K. Kim et al [9]. Then, a photolithographic process was used to form the pattern for the circular transmission line method (c-TLM). In this pattern, the radius of the inner circular contact was $400 \mu \mathrm{m}$ and the spacings between inner and outer circles ranged from $25 \mu \mathrm{m}$ to 75 $\mu \mathrm{m}$. Prior to the deposition of metal, the sample was etched in a warm solution of $\mathrm{HNO}_{3}$ and $\mathrm{HCl}$ again. The warm solution means non-boiling aqua regia : a solution was boiled and cooled for 2 3 minutes since very hot solution ruins the photoresist. The Ni ( $30 \mathrm{~nm}$ ) / $\mathrm{Au}(15 \mathrm{~nm})$ and the $\mathrm{Pd}(25 \mathrm{~nm}) / \mathrm{Au}(15 \mathrm{~nm})$ contacts were deposited by thermal evaporation and completed by liftoff. The contacts were then annealed at temperatures ranging from 400 to $700{ }^{\circ} \mathrm{C}$ for 10 minutes in a conventional furnace in an oxygen and nitrogen mixed gas ambient. In order to study the effect of cryogenic treatment, some samples were subsequently cooled by dipping in liquid nitrogen after the heat treatment, then brought to room temperature in air. Sister samples were not quenched in liquid nitrogen.

The current versus voltage (I-V) curves were measured as deposited and between each heat treatment interval. After each measurement of I-V curves, the specific contact resistance $\left(\rho_{c}\right)$ was determined by use of the c-TLM. The samples with and without cryogenic treatment showing the lowest contact resistance were examined by scanning electron microscopy (SEM) images using a model Hitachi S-4000 and atomic force microscopy (AFM) images using a model Quesant Res/stg and electron spectroscopy for chemical analysis (ESCA) depth profiles using a model Surface Science SSX-100 with an ion energy of $4.5 \mathrm{keV}$, a raster size of $2 \times 2 \mathrm{~mm}$, a sputter time per step of $1 \sim 2 \mathrm{~min}$. and a $\mathrm{x}$-ray spot size of $1000 \mu \mathrm{m}$.

\section{RESULTS}

\section{Electrical Properties}

The current versus voltage curves for the as deposited, annealed and annealed plus cryogenically treated $\mathrm{Ni} / \mathrm{Au}$ and $\mathrm{Pd} / \mathrm{Au}$ contacts to $\mathrm{p}-\mathrm{GaN}$ are shown in Figure 1. Annealed contacts shown in Figure 1 were treated in an $\mathrm{O}_{2} / \mathrm{N}_{2}$ ambient. For the as deposited case, both $\mathrm{Ni} / \mathrm{Au}$ and $\mathrm{Pd} / \mathrm{Au}$ contacts show similar behavior of non linear $\mathrm{I}-\mathrm{V}$ with a small potential barrier. However, the $\mathrm{Pd} / \mathrm{Au}$ contact reveals a lower specific 

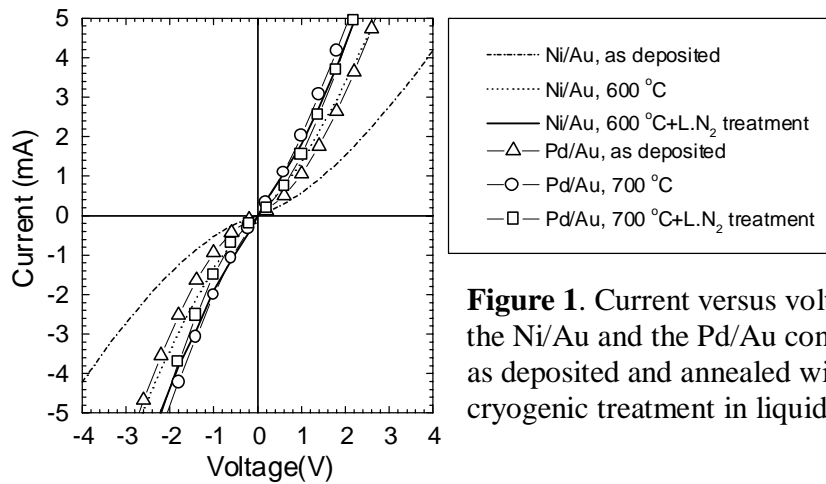

Figure 1. Current versus voltage curves for the $\mathrm{Ni} / \mathrm{Au}$ and the $\mathrm{Pd} / \mathrm{Au}$ contacts to $\mathrm{p}-\mathrm{GaN}$ as deposited and annealed with and without cryogenic treatment in liquid nitrogen.

contact resistance of $7 \sim 10 \times 10^{-4} \Omega \mathrm{cm}^{2}$ compared to $4 \sim 6 \times 10^{-2} \Omega \mathrm{cm}^{2}$ for the Ni/Au contact in the linear region, although the work function of $\mathrm{Ni}(5.15 \mathrm{eV})$ is slightly higher than $\mathrm{Pd}$ $(5.12 \mathrm{eV})$. These characteristics agree with previous studies [7,8]. We believe that the lower contact resistance of the $\mathrm{Pd} / \mathrm{Au}$ contact with lower work function of $\mathrm{Pd}$ is due to a new phase with higher work function which will be discussed from the ESCA profiles. The non linear I-V behaviors for both $\mathrm{Ni} / \mathrm{Au}$ and $\mathrm{Pd} / \mathrm{Au}$ contacts were improved by heat treatment at temperatures of $600{ }^{\circ} \mathrm{C}$ and $700{ }^{\circ} \mathrm{C}$, respectively. The reduction of the specific contact resistances to $9.84 \times 10^{-4} \Omega \mathrm{cm}^{2}$ for $\mathrm{Ni} / \mathrm{Au}$ and $1.80 \times 10^{-4} \Omega \mathrm{cm}^{2}$ for $\mathrm{Pd} / \mathrm{Au}$ were also obtained by heat treatment. Lowering the contact resistance and improving linearity may come from a more intimate contact of metal with semiconductor or any new phases having higher work function. Intimate contact leads to more current flow across the interface by breaking up some of the interfacial contamination between metal and semiconductor. Possible new compounds reduce the potential offset at the metal/ semiconductor interface by forming a layer of a compound with higher work function or causing a highly doped region. In contrast, the effect of cryogenic treatment on forming those two contacts is quite different. With further treatment by cooling in liquid nitrogen after the anneals, the $\mathrm{Ni} / \mathrm{Au}$ contact exhibits better linearity of $\mathrm{I}-\mathrm{V}$ characteristics and a contact resistance of $2.65 \times 10^{-4} \Omega \mathrm{cm}^{2}$. However, the $\mathrm{Pd} / \mathrm{Au}$ contact show opposite behavior to the $\mathrm{Ni} / \mathrm{Au}$ contact such that cryogenic treatment degrades the specific contact resistance value to $3.34 \times 10^{-4} \Omega \mathrm{cm}^{2}$. The effect of cryogenic treatment on improving Ohmic behavior could be caused by some of the semiconductor dissolving in the metal on heating and recrystallization with a high concentration of the electrically active element in solid solution on subsequent cooling [10]. It could also be due to improved morphology as explained later. Therefore, the mechanisms and the reactions at the interface between metal and semiconductor for $\mathrm{Ni} / \mathrm{Au}$ contact and $\mathrm{Pd} / \mathrm{Au}$ contact would be different.

\section{Structural properties}

Figure 2 shows ESCA depth profiles of $\mathrm{Ni} / \mathrm{Au}$ contacts heated in $\mathrm{O}_{2} / \mathrm{N}_{2}$. The ESCA depth profile for the as deposited sample of the $\mathrm{Ni} / \mathrm{Au}$ contact shows the abrupt and sharp signals corresponding to the interfaces of the $\mathrm{Au} / \mathrm{Ni} / \mathrm{GaN}$ and all of the species ( $\mathrm{Au}, \mathrm{Ni}$, $\mathrm{Ga}$ and $\mathrm{N}$ ). From the ESCA depth profile, there is no evidence of interdiffusion from 


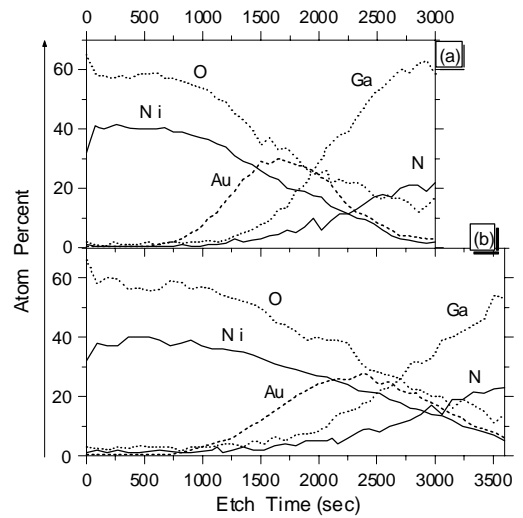

Figure 2. ESCA depth profiles for the $\mathrm{Au} / \mathrm{Ni} / \mathrm{p}-\mathrm{GaN}$ : (a) annealed at $600{ }^{\circ} \mathrm{C}$ 10 min. in $\mathrm{O}_{2} / \mathrm{N}_{2}$ and (b) annealed and cryogenically treated.

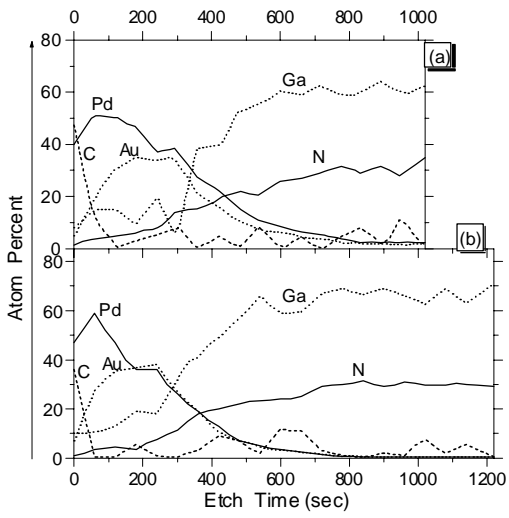

Figure 3. ESCA depth profiles for the $\mathrm{Au} / \mathrm{Pd} / \mathrm{p}-\mathrm{GaN}$ : (a) annealed at $700{ }^{\circ} \mathrm{C}$ 10 min. in $\mathrm{O}_{2} / \mathrm{N}_{2}$ and (b) annealed and cryogenically treated.

deposition alone. However, ESCA profiles change in behavior with annealing and cryogenic treatment. In the ESCA profile of an annealed sample, Figure 2(a), Ni diffused to the surface of the contact and into the $\mathrm{GaN}$. The $\mathrm{O}$ signal follows the Ni signal, which indicates a $\mathrm{NiO}$ phase. This is evident from chemical analyses, which show core levels of $\mathrm{Ni} 2 \mathrm{p}^{3} / 2$ and $\mathrm{NiO}$ at the binding energies of $852.6 \mathrm{eV}$ and $854.7 \mathrm{eV}$, respectively. On the other hand, $\mathrm{Au}$ exchanges position with $\mathrm{Ni}$ and forms an intimate contact with the $\mathrm{GaN}$ layer. These results agree with previous reports in which Ni diffused through the $\mathrm{Au}$ capping layer to the surface of the contact where it oxidized [7]. A similar behavior in ESCA depth profiles is also shown for the annealed plus cryogenic treated sample as in Figure 2(b). Our study indicates that the direct contact to $\mathrm{GaN}$ would be a combination of $\mathrm{NiO}$ and $\mathrm{Au}$. Y.Koide et al. by using x-ray diffraction (XRD) reported a NiO layer and no evidence of interaction between metals and $\mathrm{GaN}$ for the $\mathrm{Ni} / \mathrm{Au}$ contacts annealed in an $\mathrm{O}_{2} / \mathrm{N}_{2}$ ambient [6]. On the other hand, H.S. Venugopalan et al. [11] found a NiGa phase for the annealed $\mathrm{Ni} / \mathrm{n}-\mathrm{GaN}$ scheme and J.T.Trexler et al. [12] reported the possibility of a $\mathrm{Ni}-\mathrm{N}$ solid solution for the annealed $\mathrm{Ni} / \mathrm{Au}$ scheme.

The ESCA depth profiles of Pd/Au contacts are shown in Figure 3. For both contacts annealed and cryogenic treated in addition to annealing, there is no evidence of formation of PdO but of Au:Pd solid solution. This new phase ( $\mathrm{Au}: \mathrm{Pd}$ solid solution ) was reported by other groups [6,7]. The Ga and $\mathrm{N}$ signals tail out and extend out to the surface, which might indicate the decomposition of the GaN matrix. No significant difference was seen between the samples only annealed and annealed plus cryogenic treated. Note that the published sputter rate for $\mathrm{Pd}$ is $100 \mathrm{~nm} / \mathrm{min}$. compared to $60 \mathrm{~nm} / \mathrm{min}$. for $\mathrm{Ni}$.

We also examined surface morphology of those contacts using SEM. The SEM images of the as deposited samples for $\mathrm{Ni} / \mathrm{Au}$ and $\mathrm{Pd} / \mathrm{Au}$ contacts show a smooth metal surface. However, Figure 4 for the $\mathrm{Ni} / \mathrm{Au}$ contact shows the change in the surface morphology of samples annealed ( Figure 4(a) ) and cryogenic treated ( Figure 4(b) ). It clearly shows bright and gray particles within a deep dark area. From a comparison with 

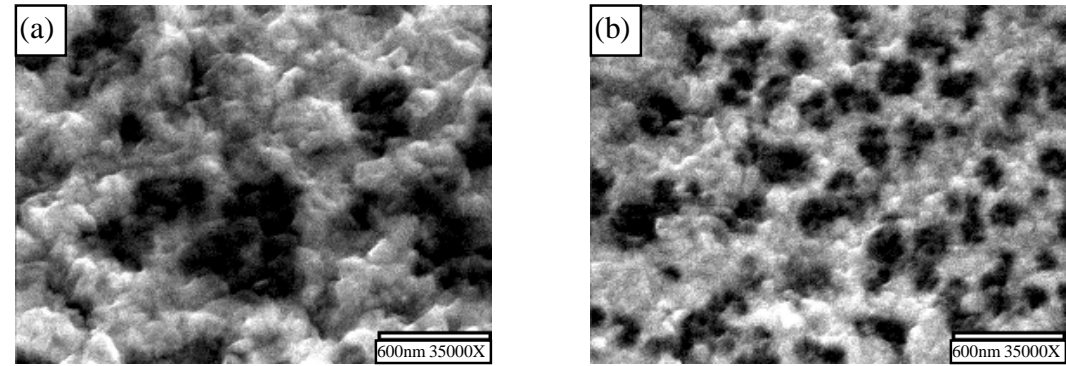

Figure 4. SEM images for the Ni/Au contacts to $\mathrm{p}-\mathrm{GaN}$ : (a) annealed at $600{ }^{\circ} \mathrm{C}$ for 10 min. in an $\mathrm{O}_{2} / \mathrm{N}_{2}$ and (b) annealed and cryogenically treated.
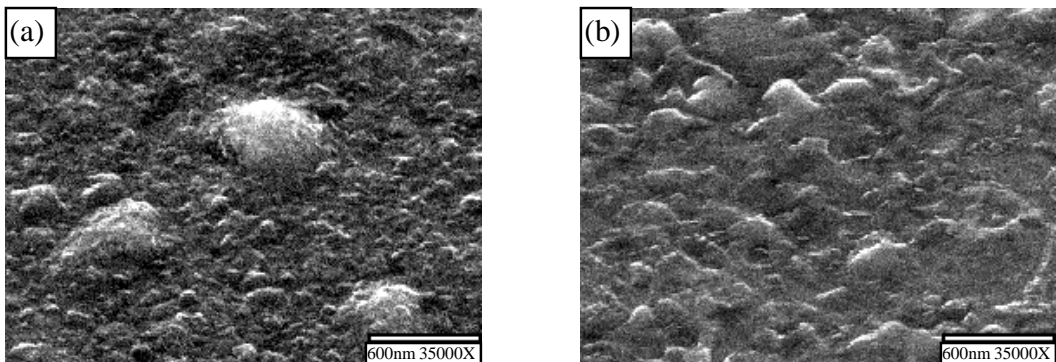

Figure 5. SEM images for the $\mathrm{Pd} / \mathrm{Au}$ contacts to $\mathrm{p}-\mathrm{GaN}$ : (a) annealed at $700{ }^{\circ} \mathrm{C}$ for 10 min. in an $\mathrm{O}_{2} / \mathrm{N}_{2}$ and (b) annealed and cryogenically treated.

composition vs. depth in ESCA profiles, the bright and gray particles are $\mathrm{NiO}$ and black areas would be the mixing of the transition metal oxide ( $\mathrm{NiO}$ ) and $\mathrm{Au}$ which directly contacts with GaN. Figure 4(b) shows that the cryogenic treated sample has a smaller dark area (black) and smoother surface of $\mathrm{NiO}$ ( bright and gray ) than the other (Figure 4(a)). For the Pd/Au contacts in Figure 5, we can see a difference in particle size but not in roughness. The sample not cryogenic treated, in Figure 5(a), has non uniform larger particles. Contrary to this feature, the sample with liquid nitrogen cooling shows almost uniform particles. We believe that the "balling-up" of the NiO layer occurs during the heating process from the compressive stress due to the difference of the thermal expansion coefficients between $\mathrm{Ni}\left(13.3 \times 10^{-6} \mathrm{~K}^{-1}\right)[13], \mathrm{Au}\left(14.1 \times 10^{-6} \mathrm{~K}^{-1}\right)$ [13], $\operatorname{Pd}\left(11 \times 10^{-6} \mathrm{~K}^{-1}\right)$, and $\mathrm{GaN}\left(6 \times 10^{-6} \mathrm{~K}^{-1}\right)$ [14]. The differences in surface features for the contacts with and without cryogenic treatment are in size and thickness of the different colored regions. In addition to the effect of compressive stress, strain is also induced during cooling due to the difference of thermal expansion coefficients of materials. Therefore, we suggest that subsequent and fast cooling in liquid nitrogen minimizes the effect of compressive stress and strain, then results in the laterally more uniform surface which is significant in the electrical properties. This is supported by AFM data which show the surface roughness of the Ni/Au contact. The average values of the surface roughness are $64.78 \mathrm{~nm}$ and $37.38 \mathrm{~nm}$ for the contacts annealed only compared to those treated in liquid nitrogen after annealing, respectively. There is 
no much difference in the values of the surface roughness : $54.46 \mathrm{~nm}$ for annealed and $68.2 \mathrm{~nm}$ for annealed plus cryogenic treated, for the Pd/Au contacts from the AFM images.

\section{CONCLUSIONS}

Both $\mathrm{Ni} / \mathrm{Au}$ and $\mathrm{Pd} / \mathrm{Au}$ contacts to $\mathrm{p}-\mathrm{GaN}$ show Ohmic behavior with and without a cryogenic treatment. The cryogenic treatment on the Ni/Au contacts improves the I-V linearity and reduces the specific contact resistance from $9.84 \times 10^{-4} \Omega \mathrm{cm}^{2}$ to $2.65 \times 10^{-4}$ $\Omega \mathrm{cm}^{2}$. The phases $\mathrm{NiO}$ and Au:Pd have been observed for both contact systems, respectively. Subsequent and fast cooling in liquid nitrogen after anneal affects the recrystallizing of $\mathrm{NiO}$ and $\mathrm{Au}: \mathrm{Pd}$ solid solution produced from heat treatment, then improves surface morphology. The contact resistance is improved by: i) heat temperature which forms new phases at the GaN surface compared to the initial deposit; and ii) cryogenic treatment which affects both the recrystallization and surface morphology.

\section{REFERENCES}

1. S. Nakamura, M. Senoh, N. Iwasa, and S. Nagahama, Jpn. J. Appl. Phys. 34, L797(1995).

2. S. Nakamura, M. Senoh, N. Iwasa, S. Nagahama, T. Yamada, and T. Mukai, Jpn. J. Appl. Phys. 34, L1332(1995).

3. S. Nakamura, and M. Senoh, Jpn. J. Appl. Phys. 30, L1998(1991).

4. S, Nakamura, M. Senoh, S. Nagahama, N. Iwasa, T. Yamada, T. Matsushita, H. Kiyoku, and Y. Sugimoto, Jpn. J. Appl. Phys. 35, L217(1996).

5. P. H. Holloway, T-J. Kim, J. T. Trexler, S. Miller, J. J. Fijol, W. V. Lampert, T. W. Haas, Appl. Sur. Sci., 117/118, 362(1997).

6. Y. Koide, T. Maeda, T. Kawakami, S. Fujita, T. Uemura, N. Shibata, and M. Murakami, J. Elec, Mat., V28. 341(1999).

7. J. T. Trexler, S. J. Pearton, P. H. Holloway, M. G. Mier, K. R. Evans, and R. F. Karlicek, Mat. Res. Soc. Symp. Proc., V449, 1091(1997).

8. T. Kim, J. Khim, S. Chae, and T. Kim, Mat. Res. Soc. Symp. Proc., V468, 427(1997).

9. J. K. Kim and J. Lee, Appl. Phy. Lett., 73, 2953(1998).

10. E. H. Rhoderick and R. H. Williams, "Metal-Semiconductor contacts", Clarendon, $2^{\text {nd }}, \mathrm{P} 206(1988)$.

11. H. S. Venugopalan, S. E. Mohney, B. P. Luther, J. M. Delucca, S. D. Walter, J. M. Redwing, and G. E. Bulman, Mat. Res. Soc. Symp. Proc., V468, 431(1997).

12. J. T. Trexler, S. J. Miller, P. H. Holloway, M. A. Kwan, Mat. Res. Soc. Symp. Proc., V395, 819(1996).

13. E. A. Brandes, "Smithells Metals Reference Book", Batterworths, $6^{\text {th }}$ Ed.

14. K. J. Duxstad, E. E. Haller, K. M. Yu, M. T. Hirsch, W. R. Imler, D. A. Steigerwald, F. A. Ponce, and L. T. Romano, Mat. Res. Soc. Symp. Proc., V449, 1049(1997). 